\title{
DESIDRATAÇÃO DE MAÇÃS (MALUS DOMESTICA L.) UTILIZANDO SECAGEM A AR ASSISTIDA POR ULTRA-SOM
}

\author{
F.A.N FERNANDES ${ }^{1}$, S. RODRIGUES ${ }^{2}$, J.V.GARCIA-PEREZ ${ }^{3}$ e J.A. CARCEL ${ }^{3}$ \\ 1 Universidade Federal do Ceará, Departamento de Engenharia Química \\ 2 Universidade Federal do Ceará, Departamento de Tecnologia de Alimentos \\ 3 Universitat Politécnica de Valencia, Departamento de Tecnologia de \\ Alimentos \\ E-mail para contato: fabiano@ufc.br
}

\begin{abstract}
RESUMO - Este trabalho analisou a influência da secagem de maçãs assistida por ultrasom e sua influência na disponibilidade de vitaminas $A, B_{1}, B_{2}, B_{3}, B_{5}, B_{6}$, D e E no produto final. Este estudo permitiu estimar a difusividade efetiva da água nos processos de secagem com e sem aplicação de ultrassom. A difusividade efetiva da água aumentou em até $79 \%$ com a aplicação de ultrassom, causando a redução no tempo de secagem em até $35 \%$. Um efeito negativo do processo de secagem foi observado na disponibilidade das vitaminas B5 e E. Porém a aplicação do ultrassom foi responsável pelo incremento na disponibilidade de vitaminas $\mathrm{A}, \mathrm{B}_{1}, \mathrm{~B}_{2}, \mathrm{~B}_{3}, \mathrm{~B}_{6}$ e $\mathrm{D}$, liberando a vitamina de sua ligação com a membrana celular, proteínas ou apoenzima.
\end{abstract}

\section{INTRODUÇÃO}

As atuais tendências da sociedade, incluindo a redução dos níveis de atividade física e o aumento da disponibilidade de produtos alimentares baratos de baixa qualidade nutricional e alto teor calórico, contribuíram para preocupações com relação as dietas atuais nos países desenvolvidos. Os consumidores se tornaram mais conscientes das diferentes dietas e seu impacto sobre a saúde, e as empresas de alimentos e os comerciantes começaram a dedicar mais tempo e esforço para desenvolver produtos mais saudáveis e mais nutritivos.

O processo de secagem reduz o teor de umidade do produto diminuindo o efeito de um dos principais fatores que determinam a taxa de deterioração de vitaminas por várias reações bioquímicas, a atividade de água (Ball, 2006). No entanto, o processo de secagem pode aumentar a perda de vitamina, aumentando a exposição do alimento à alta temperatura durante um período de tempo.

Embora a secagem de produtos vegetais é geralmente realizada em temperaturas amenas para evitar perda de nutrientes e degradação de cor, um longo tempo de exposição acaba deteriorando a qualidade nutricional do produto. Novos processos foram desenvolvidos para encurtar o tempo de secagem, tais como pré-tratamentos assistidos por ultra-som e por 
microondas (Garcia-Perez et al. 2006; Carcel et al. 2007; Delgado et al 2009; Fernandes et al, 2010).

A secagem convencional é um processo simultâneo de transferência de calor e de massa, acompanhada de mudança de fase, sendo um processo de alto custo. Geralmente, um tipo de prétratamento é usado para reduzir o teor de água inicial ou modificar a estrutura do tecido de frutas para reduzir o total de tempo de processamento de secagem. Neste trabalho, a utilização de secagem a ar assistido por ultra-som foi investigado.

Ondas ultra-sônicas podem causar uma série rápida de compressões e expansões, de forma semelhante a uma esponja quando é espremida repetidamente (efeito de esponja). Além disso, o ultra-som produz cavitações que podem ser benéficas para a remoção de umidade fortemente ligada ao sólido.

A biodisponibilidade de vitaminas varia de acordo com a forma química e estado físico no qual a vitamina existe dentro da matriz alimentar. Em alimentos derivados de plantas, as vitaminas do grupo B ocorrem ligadas a coenzimas, geralmente associados com uma apoenzima de proteína ou em sua forma livre. Vitaminas que existem como complexos e estão ligadas com algum outro material na matriz alimentar tem maior dificultade de digestão e menor absorção pelo intestino em comparação com a forma livre da vitamina (Ball, 2006).

Novas tecnologias para a produção de produtos alimentares devem visar não somente a conservação de alimentos, mas também devem melhorar o conteúdo nutricional do alimento. $\mathrm{O}$ processamento de alimentos tem de aumentar o valor nutricional do produto final e no caso de vitaminas devem converter a vitamina em sua forma livre, aumentando sua biodisponibilidade total.

As maçãs são uma das principais frutas consumidas em todo o mundo e fazem também parte em muitos produtos alimentares. As maçãs são boa fonte de vitaminas B2, B3, B5, B6 e também contêm vitaminas A, B1, D e E em quantidades menores.

Neste trabalho, o uso da secagem assistida por ultra-som assistida foi investigada na secagem de maçãs. A influência da secagem assistida por ultra-som foi avaliada sobre a difusividade efetiva da água e o teor de vitaminas A, B1, B2, B3, B5, B6, D e E. O aumento da disponibilidade ou a perda de vitaminas no produto desidratado foram discutidos.

\section{MATERIAIS E MÉTODOS}

\subsection{Preparação de amostras}

Maçãs (Malus domestica L. var. Royal Gala) foram compradas no mercado local (Valencia, Espanha). Foram utilizados apenas os frutos com a mesma fase de maturidade. As maçãs foram cortadas em cubos com espessura média de $8,5 \mathrm{~mm}$. 
O teor de umidade dos frutos foi determinado por secagem a $60{ }^{\circ} \mathrm{C}$ sob vácuo $(50 \mathrm{mmHg})$ até peso constante (24 horas).

\subsection{Secagem}

A secagem das maçãs foram realizadas em um secador convectivo assistido por ultra-som (Ortuño et al., 2010). Nesta configuração, um dispositivo ultra-sônico em ar constitui a câmara de secagem, que é composta por um cilindro de alumínio acoplado a um transdutor piezoelétrico $(21,7 \mathrm{kHz})$.

Foram realizados experimentos secando de amostras de maçã em quatro velocidades de ar diferentes $(1,2,3$ e $5 \mathrm{~m} / \mathrm{s})$ e duas temperaturas $\left(45\right.$ e $\left.60^{\circ} \mathrm{C}\right) \operatorname{com}(75 \mathrm{~W} ; 21 \mathrm{kHz})$ e sem aplicação de ultra-som. Os experimentos de secagem foram concluídos quando as amostras perderam $80 \%$ do seu peso inicial.

A cinética de secagem da maçã foi modelada assumindo a transferência de massa controlada por difusão com o fluxo de líquido dentro da fruta em conformidade com a segunda lei de Fick. O modelo utilizado considera a solução da segunda lei de Fick para amostras em forma cúbicas.

$$
\frac{W-W_{e q}}{W_{c r i t}-W_{e q}}=\sum_{n=0}^{\infty} \frac{8}{(2 n+1)^{2} \pi^{2}} \exp \left(\frac{-(2 n+1)^{2} \pi^{2} D t}{4 L^{2}}\right)
$$

Dados experimentais foram utilizados para estimar o coeficiente de difusão efetivo do processo de secagem. O parâmetro foi ajustado com um processo de estimativa de parâmetros baseado na minimização da soma dos quadrados dos erros.

\subsection{Determinação de vitaminas}

A concentração de vitaminas $A, \quad D$ e $E$ em maçãs foi determinada espectrofotometricamente. A análise foi baseada em métodos revisados por Jedlicka e Klimes (2005) e Rizzolo e Polesello (1992).

Uma amostra de $1 \mathrm{~g}$ de fruta foi homogeneizada com $6 \mathrm{~mL}$ de água destilada por $2 \mathrm{~min}$ usando um homogeneizador de célula (modelo Ultraturrax IKA T25). Hidróxido de sódio 0,5 M $(1 \mathrm{~mL})$ foi adicionado à amostra, que foi transferida $30 \mathrm{~min}$ para um banho de água a $70{ }^{\circ} \mathrm{C} \mathrm{e}$ deixado por $30 \mathrm{~min}$.

Após resfriamento à temperatura ambiente em um banho de gelo, hexano $(5 \mathrm{~mL})$ foi adicionado e a mistura foi agitada vigorosamente durante $1 \mathrm{~min}$. O sobrenadante que contém as vitaminas liposolúveis foi recolhido e analisado por espectrometria a 215, 325 e $254 \mathrm{~nm}$.

Os resultados foram expressos como a ganho/perda de vitamina usando a fruta fresca como referência (base seca). 
A concentração de vitaminas do complexo B também foi determinada por espectrometria com base em métodos revisados por Jedlicka e Klimes (2005) e Rizzolo e Polesello (1992). Neste caso, $1 \mathrm{~g}$ de fruta foi homogeneizada com $6 \mathrm{~mL}$ de água destilada por $2 \mathrm{~min}$ usando um homogeneizador de células (modelo Ultraturrax IKA T25). Ácido sulfúrico 0,25 M (1 mL) foi adicionado à amostra, que foi transferida para um banho de água a $70{ }^{\circ} \mathrm{C}$ e mantido por 30 min nestas condições.

Após o resfriamento da amostra à temperatura ambiente em um banho de gelo, o pH da mistura foi ajustado a pH 4.5 usando uma solução de hidróxido de sódio $0,5 \mathrm{M}$. A amostra foi centrifugada a $10000 \mathrm{rpm}(8400 \times \mathrm{g})$ por $10 \mathrm{~min}$. $\mathrm{O}$ sobrenadante que contém as vitaminas hidrosolúveis foi recolhido e analisado por espectrometria a 215, 254, 265 e $716 \mathrm{~nm}$.

\section{RESULTADOS E DISCUSSÕES}

\subsection{Experimentos de secagem}

A maçã apresentou um teor de umidade inicial de $83.9 \pm 0,5 \mathrm{~g} / 100 \mathrm{~g}$ de fruta fresca (base úmida). Em termos gerais, aplicação de ultra-som reduziu o tempo necessário para a secagem das maçãs.

A vantagem na aplicação do ultra-som aumentou a baixas velocidade de ar e quando temperaturas mais baixas foram utilizadas, como observado comparando a difusividade efetiva de água para cada condição (Tabela 1).

Tabela 1. Difusividade efetiva de água para cubos de maçã em diferentes temperaturas e velocidades do ar.

\begin{tabular}{cccc}
\hline $\begin{array}{c}\text { Temp. } \\
\left({ }^{6} \mathrm{C}\right)\end{array}$ & $\begin{array}{c}\text { Velocidade do ar } \\
(\mathrm{m} / \mathrm{s})\end{array}$ & $\begin{array}{c}\text { Difusividade } \\
\text { com ultra-som } \\
\left(\times 10^{9} \mathrm{~m}^{2} \mathrm{~s}^{-1}\right)\end{array}$ & $\begin{array}{c}\text { Difusividade } \\
\text { sem ultra-som } \\
\left(\times 10^{9} \mathrm{~m}^{2} \mathrm{~s}^{-1}\right)\end{array}$ \\
\hline 45 & 1 & $0,89 \pm 0,03$ & $0,58 \pm 0,02$ \\
& 2 & $1.12 \pm 0,04$ & $0,73 \pm 0,03$ \\
& 3 & $1.26 \pm 0,09$ & $0,81 \pm 0,04$ \\
60 & 5 & $1,42 \pm 0,08$ & $1.28 \pm 0,10$ \\
& 1 & $1,32 \pm 0,05$ & $0,91 \pm 0,03$ \\
& 2 & $1,61 \pm 0,06$ & $1.12 \pm 0,03$ \\
& 5 & $1,73 \pm 0.07$ & $1,55 \pm 0,08$ \\
& 5 & $1,89 \pm 0,10$ & $1,89 \pm 0,05$ \\
\hline
\end{tabular}

A $45^{\circ} \mathrm{C}$ e $1 \mathrm{~m} / \mathrm{s}$ de velocidade do ar, a difusividade efetiva de água para o processo de secagem assistido por ultra-som foi $54 \%$ maior do que o processo convencional e a redução de 
tempo foi de $35 \%$, A $60{ }^{\circ} \mathrm{C}$ e $5 \mathrm{~m} / \mathrm{s}$ ambos os parâmetros foram semelhantes para o processo com aplicação de ultra-som e sem aplicação de ultra-som.

A redução no tempo de secagem observada para maçãs esta dentro do intervalo observado para outras frutas e legumes, como relatado por Carcel et al (2007), García-Pérez et al. (2009), Ozuna et al (2011) e Puig et al (2012).

\subsection{Disponibilidade de vitaminas em maças desidratadas}

A quantidade relativa de vitaminas nas maçãs submetidas a secagem assistida por ultrasom (em base seca) é apresentada nas Figuras 1 e 2, respectivamente para vitaminas solúveis em água (B1 + B2, B3, B5 e B6) e vitaminas lipossolúveis (A, D e E). A quantidade relativa foi calculada considerando a quantidade de vitamina na maçã in natura como $100 \%$.

A quantidade de vitaminas B1 + B2 aumentou durante a secagem para experimentos com e sem aplicação de ultra-som. Parte da vitamina B2 (riboflavina) é ligada firmemente a uma apoenzima, enquanto a vitamina B1 (tiamina) é normalmente encontrada na forma livre ou fosforilada (Ball, 2006). Os resultados sugerem que a aplicação de ultra-som durante a secagem e o tratamento térmico foram capazes de quebrar a ligação entre a vitamina e a apoenzima, alterando-a para sua forma livre e biodisponível.

$\mathrm{O}$ efeito do ultra-som parece ser positivos em baixa temperatura e observou-se uma tendência de aumentar a disponibilidade da vitamina. Em alguns casos, a quantidade de vitaminas B1 + B2 nas amostras secas com aplicação de ultra-som foi ligeiramente maior do que para a secagem convencional indicando que o ultra-som pode induzir um maior desprendimento de vitaminas de sua ligação com a apoenzima.

A quantidade de vitamina B3 aumentou após a secagem sem aplicação de ultra-som. A degradação da vitamina B3 foi observada em apenas duas condições operacionais onde foi aplicado ultra-som. A vitamina B3 é quimicamente ligada a nucleotídeos e até $70 \%$ de niacina pode ser biologicamente indisponível em alimentos crus (Guimaraes et al. 1963; Wall e Carpenter, 1988). Os resultados indicaram que a temperatura e a aplicação de ultra-som durante a secagem podem afetar a vitamina. A quantidade de vitamina B3 foi superior a $45^{\circ} \mathrm{C}$. A aplicação de ultra-som durante a secagem teve um efeito significativo nas experiências efetuadas a $60{ }^{\circ} \mathrm{C}$ e as velocidades de ar mais elevadas ( 3 e $5 \mathrm{~m} / \mathrm{s}$ ) proporcionando uma maior disponibilidade de vitamina B3.

O processo de secagem levou a uma redução na quantidade de vitamina B5 (ácido pantotenóico). Apenas a condição de secagem mais rápida com aplicação de ultra-som foi capaz de apresentar um aumento líquido em vitamina B5. Nenhuma tendência óbvia foi observada para o processo convencional. A aplicação de ultra-som durante a secagem a $60{ }^{\circ} \mathrm{C}$ mostrou um efeito negativo na vitamina B5 em função do tempo de processamento (menor velocidade do ar), com o aumento na perda de vitamina. 
A secagem convencional e assistida por ultra-som aumentou a quantidade de vitamina B6 livre, que aumentou para tempos mais longos de processamento. $\mathrm{O}$ ultra-som apresentou um efeito positivo e a quantidade de vitamina B6 foi maior nas amostras secas com aplicação de ultra-som. Baixas temperaturas de processamento resultaram em uma maior quantidade de vitamina B6 na maçã seca.

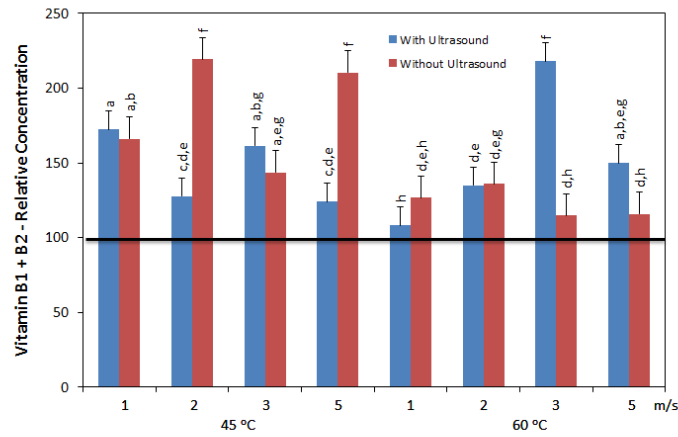

(a)

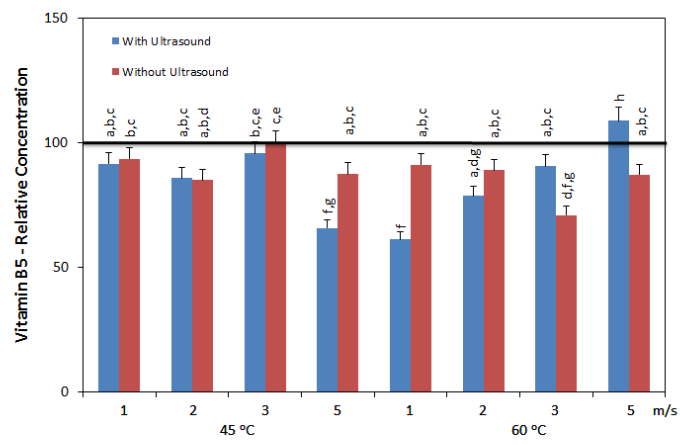

(c)

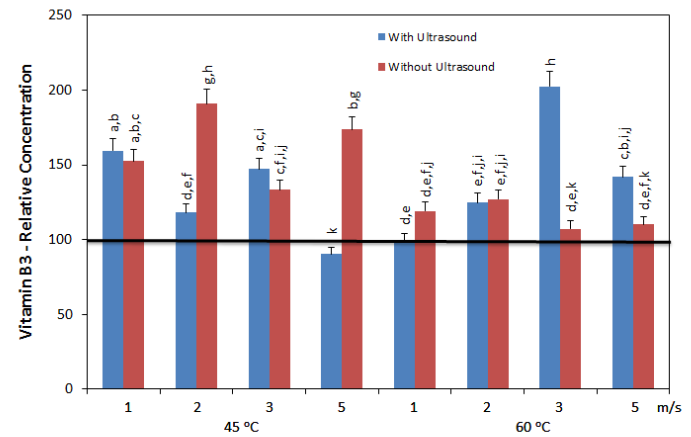

(b)

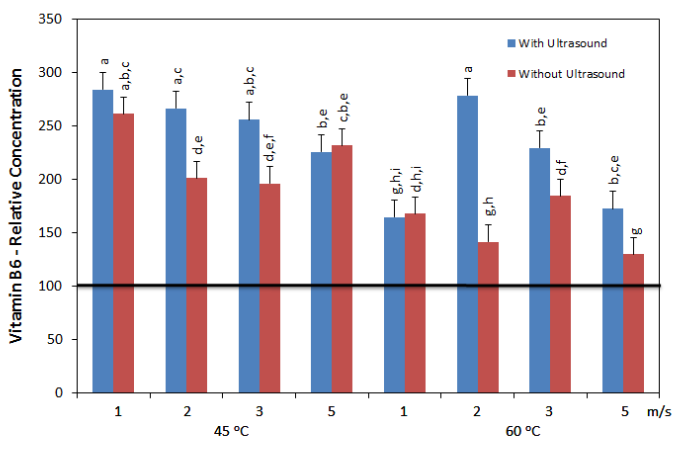

(d)

Figura 1. Influência da temperatura, velocidade do ar e aplicação do ultra-som na quantidade de vitaminas B em maçãs. (a) vitaminas B1 + B2; (b) vitamina B3; (c) vitamina B5; e (d) vitamina B6.

As vitaminas lipossolúveis apresentaram tendências similares dentro deste grupo de vitaminas (A, D e E). O ultra-som teve um efeito positivo no processo de secagem mais curto, mas um efeito negativo significativo como o aumento no tempo de processamento, levando a perda de vitaminas.

As vitamina A e D são encontradas geralmente associadas a membrana celular e lipoproteínas. $\mathrm{O}$ processamento com ultra-som mostrou boa e rápida resposta para produzir a forma livre de vitaminas A e D. A retenção da vitamina $\mathrm{E}$ foi muito baixa, com média de $51 \%$ de retenção. A perda da vitamina $\mathrm{E}$ foi maior no processo com aplicação de ultra-som do que no processo convencional. O comportamento de eliminação radical da vitamina E pode desempenhar um papel em seu consumo durante a secagem, uma vez que a aplicação do ultra-som induz a 
produção de pequena quantidade de radicais livres, na matriz de frutas, que será atacado pela vitamina E.

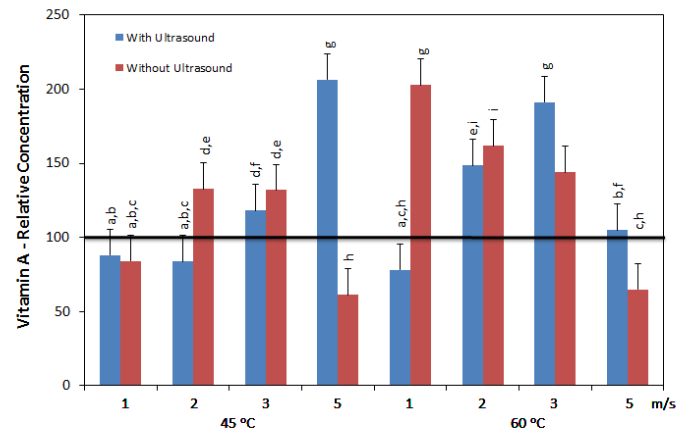

(a)

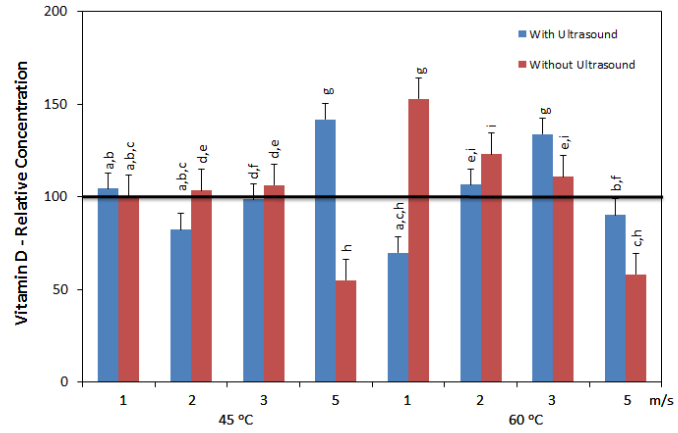

(b)

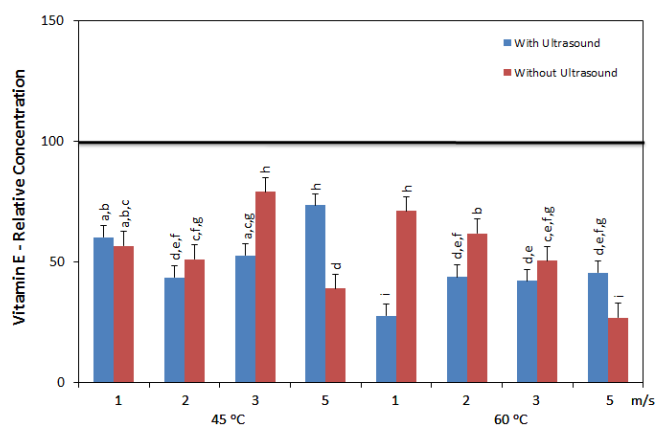

(c)

Figura 2. Influência da temperatura, velocidade do ar e aplicação de ultra-som na quantidade de vitaminas A (a), D (b) e E (c) em maçãs.

\section{CONCLUSÃO}

A aplicação de ultra-som aumenta a difusividade efetiva de água em maçãs e reduziu o tempo de secagem. A influência foi mais intensa em baixas velocidades do ar e temperaturas de secagem. A aplicação do ultra-som foi capaz de ajudar a aumentar a disponibilidade da forma livre de vitaminas A, B1, B2, B3, B6 e D. A degradação da vitamina B5 e E ocorreu em um grau mais elevado. A aplicação do ultra-som permite o uso de temperaturas de secagem mais altas sem comprometer a qualidade nutricional de maçãs secas quanto ao teor de vitamina

\section{AGRADECIMENTOS}

Os autores agradecem o apoio financeiro do $\mathrm{CNPq}$ e do Ministerio de Economía y competitividade da Espanha. 


\section{REFERÊNCIAS}

BALL, G.F.M. Vitamins in Foods: Analysis, Bioavailability, and Stability. Boca Raton, USA: CRC Press, 2006.

CÁRCEL, J.A.; BENEDITO, J.; ROSSELLÓ, C.; MULET, A. Influence of Ultrasound Intensity on Mass Transfer in Apple Immersed in a Sucrose Solution. Journal of Food Engineering 78, 472-479, 2007.

CÁRCEL, J.A.; GARCÍA-PÉREZ, J.V.; RIERA, E.; MULET, A. Influence of High Intensity Ultrasound on Drying Kinetics of Persimmon. Drying Technology 25: 185-193, 2007.

DELGADO, A.E.; ZHENG, L.; SUN, D.W. Influence of Ultrasound on Freezing Rate of Immersion-Frozen Apples. Food and Bioprocess Technology 2: 263-270, 2009.

FERNANDES, F.A.N., RODRIGUES, S; LAW, C.L.; MUJUMDAR, A.S. Drying of Exotic Tropical Fruits: A Comprehensive Review. Food and Bioprocess Technology 4, 163-185, 2010.

GARCÍA-PÉREZ, J.V.; CÁRCEL, J.A.; RIERA, E.; MULET, A. Influence of the Applied Acoustic Energy on the Drying of Carrots and Lemon Peel. Drying Technology 27: 281-287, 2009.

GARCIA-PEREZ, J.V.; CÁRCEL, J.A.; FUENTE-BLANCO, S.; RIERA-FRANCO DE SARABIA, E. Ultrasonic Drying of Foodstuff in a Fluidized Bed: Parametric Study. Ultrasonics 44 Suppl 1: e539-e543, 2006.

GHOSH, H.P.; SARKAR, P.K.; GUHA, B.C. Distribution of the Bound Form of Nicotinic Acid in Natural Materials. The Journal of Nutrition 79: 451-453, 1963.

JEDLICKA, A.; KLIMES, J. Determination of Water- and Fat-Soluble Vitamins in Different Matrices Using High-Performance Liquid Chromatography. Chem. Pap. 59: 202-222, 2005.

ORTUÑO, C.; PEREZ-MUNUERA, I.; PUIG, A.; RIERA, E.; GARCÍA-PÉREZ, J.V. Influence of Power Ultrasound Application on Mass Transport and Microestructure of Orange Peel during Hot Air Drying. Physics Procedia 3: 153-159, 2010.

OZUNA, C.; CÁRCEL, J.A.; GARCIA-PEREZ, J.V.; MULET, A. Improvement of Water Transport Mechanisms during Potato Drying by Applying Ultrasound. Journal of the Science of Food and Agriculture 91: 2511-2517, 2011.

PUIG, A.; PEREZ-MUNUERA, I.; CÁRCEL, J.A.; HERNANDO, I.; GARCIA-PEREZ, J.V. Moisture Loss Kinetics and Microstructural Changes in Eggplant (Solanum Melongena L.) during Conventional and Ultrasonically Assisted Convective Drying. Food and Bioproducts Processing 90: 624-632, 2012.

RIZZOLO, A.; POLESELLO, S. Chromatographic Determination of Vitamins in Foods. Journal of Chromatography 624: 103-152, 1992.

WALL, J.S.; CARPENTER, K.J. Variation in Availability of Niacin in Grain Products. Food Technology 42: 198-204, 1988. 